\title{
Peers or pariahs? The quest for fairer conditions for international medical graduates in Australia
}

\section{Implementing recommendations of the parliamentary inquiry and international codes of practice on employment of IMGs}

$\mathrm{t}$ has been more than 2 years since the final report of the inquiry into the registration processes and support for overseas-trained doctors ${ }^{1}$ was tabled in Parliament. The scope of the inquiry was extensive, involving over 200 submissions and 22 public hearings held in 12 different locations across Australia. In the foreword of the report, entitled Lost in the labyrinth, Steve Georganas, Chair of the Committee, acknowledged that "whilst IMGs [international medical graduates] generally have very strong community support, [they] do not always receive the same level of support from institutions and agencies that accredit and register them".1 The report outlined 45 recommendations which, if implemented, would create a fairer registration and accreditation system without compromising patient safety.

In spite of the significant cost of the inquiry, borne by taxpayers, its recommendations have yet to be formally endorsed by the federal government. This is not a new situation. Over the past 25 years, a number of major inquiries have investigated the fairness and/ or effectiveness of the registration and accreditation system, but have largely failed to produce meaningful improvements. ${ }^{2}$ For instance, in 2005 the Australian Competition and Consumer Commission and Australian Health Workforce Officials' Committee recommended fairer methods of assessing and recognising the credentials of overseas-trained specialists, but those recommendations were not fully implemented either.

The failure to implement meaningful reforms in line with the recommendations has meant that the current two-tier system for IMGs and Australiantrained doctors persists. These differences arise from a complex array of registration, accreditation, immigration and workforce policies, which perpetuates a multifaceted process of discrimination and exploitation of qualified medical practitioners. ${ }^{3}$

A case in point is section $19 \mathrm{AB}$ of the Health Insurance Act 1973 (Cwlth), more widely known as the 10-year moratorium. The moratorium stipulates that IMGs must work in underserviced areas for up to 10 years. This restriction is unparalleled in the developed world. Not only does it cause significant personal hardship, family stress and cultural isolation, it also places limits on professional development and career opportunities.

In addition, the 10-year moratorium may be ineffective as a strategy to sustainably increase the number of doctors in rural Australia. Results of a study examining career progressions of doctors 5 years after they completed their training in rural practices showed that $73 \%$ of Australian-born doctors remained working in rural practice, whereas only $23 \%$ of IMGs followed a similar career path. ${ }^{4}$ Australian-born doctors choose to remain in rural practice because of their familiarity with a country lifestyle and the presence of a support network for spouses and children. However, "lack of familiarity with rural living and isolation from family and friends ${ }^{\prime \prime 4}$ were reasons mentioned to account for the relocation of most of IMGs to urban settings after they had satisfied the regulatory mechanisms that compelled them to remain in rural areas.

The author of a Prairie Centre of Excellence for Research on Immigration and Integration working paper stated that, in Canada, placement schemes under which IMGs from overseas are recruited to work under limited registration in remote regions "have not provided a long-term solution for provinces seeking to address the needs of under served areas". ${ }^{5}$ He concluded that placing IMGs in underserved areas has produced a "medical carousel" of IMGs leaving rural areas once they obtain their unrestricted licenses. ${ }^{5}$ Given the failure of such a policy to produce its intended results in a country with an arguably comparable health care system, the 10-year moratorium should be progressively phased out in Australia. In the Lost in the labyrinth report, the Chair concluded that "a review of the 10 year moratorium would be appropriate and timely".1.

Many of the doctors recruited to redress health care workforce shortages were never informed about the restrictions they would be subject to on their arrival in Australia. Yet, pursuant to section 72 of the Health Practitioner Regulation National Law (enacted in all states and territories), any IMG on a Temporary Work (Skilled) (subclass 457) visa who, for any reason, ceases to be registered with the Medical Board of Australia, will be left with only 28 days to find an immediate alternative or leave the country. Also, there is no fair appeal and grievance process for IMGs with 457 visas, many of whom work in designated Area of Need (AoN) positions. The impact of restrictive policies on the personal and professional lives of IMGs in Australia has been ruinous. For example, doctors with 457 visas and their families do not qualify for health care services under Medicare. In a recent case in rural Queensland, a United States-born doctor had to pay a thousand dollars for treating his own daughter's broken arm while he was on duty at the local hospital. ${ }^{6}$ Overseas-trained doctors and nurses are intrinsically involved with providing health services under Medicare, a characteristic not shared with any other group of temporary worker in Australia. 
An independent integrity review commissioned by the Ministry for Immigration and Citizenship ${ }^{7}$ confirmed that 457 visa holders are potentially vulnerable to exploitation. For example, IMGs have reportedly been forced to work up to 80 hours per week, as documented in one of the submissions to the parliamentary inquiry ${ }^{1}$ (submission 101, page 75 ). The current system contravenes recommendations of major government policy reviews. The first recommendation of the final report of the Visa Subclass 457 Integrity Review advises that subclass 457 visa holders should "have the same terms and conditions of employment as all other employees in the workplace".

In addition, the Commonwealth code of practice for the international recruitment of health workers, adopted by Commonwealth Health Ministers in 2003, determined that IMGs should be "protected by the same employment regulations and have the same rights" as their local counterparts. ${ }^{8}$ Similarly, The World Health Organization Global code of practice on the international recruitment of health personnel, adopted by the 63rd World Health Assembly in 2010, of which Australia was a signatory member, established that migrant health personnel should "enjoy the same legal rights and responsibilities as the domestically trained health workforce in all terms of employment and conditions of work". 9

In Australia, IMGs who attained medical qualifications in the United Kingdom, United States, Canada, New Zealand and Ireland are entitled to an accelerated registration process (competent authority pathway), whereas IMGs who qualified elsewhere must undergo a multiple choice examination and a structured clinical assessment (standard pathway). Local graduates are not required to undergo a similar formal assessment. The waiting period to sit for the clinical component can be long, which may curtail employment opportunities for many IMGs. The procedures involved in the registration and integration of IMGs have been described as not ideal. ${ }^{10}$

Workplace based assessment (WBA) is an alternative route based on a 6-month assessment process, which can also be delivered in regional Australia. Entry into the WBA program has the same eligibility criteria as the standard pathway, which includes an English language proficiency test. It has been shown that the WBA is a cost-effective form of assessment that facilitates a straightforward integration of doctors into the local health care system. ${ }^{10}$ The committee that conducted the parliamentary inquiry recommended that colleges of specialists also adopt the WBA model to assess the clinical competence of specialist IMGs (recommendation 8, chapter 4, page 96), given that this assessment methodology is "a much more reliable and accurate evaluation of clinical skills of the IMG" (chapter 4, page 84$)^{1}$

Notwithstanding the recommendations of the parliamentary enquiry, ${ }^{1}$ the WBA remains available only in a limited number of training sites for nonspecialists, and only a limited number of colleges of specialists have incorporated the WBA into their evaluation processes. Many overseas-trained specialists remain working in AoN positions for years when this period could have counted towards their registrations through WBA. There remain colleges who still insist on using simulated assessment conditions to determine whether a colleague and specialist in his or her own right is sufficiently qualified to practise in a jurisdiction where he or she has in fact been practising competently for several years.

There is no argument that patient safety must be the number one consideration in recommending reforms to the system. A central conclusion of the Lost in the labyrinth report was that "improvements in registration processes for IMGs must be achieved without compromising the high standards that Australians expect from medical practitioners". Yet, there remain the flagrant breaches of the codes of practice mentioned above, which buttress a de-facto two-tier system in Australia whereby disempowered IMGs have to bear the burden of hindrances that do not apply to local graduates. These discriminatory policies are ethically indefensible, given the overt violations of principles of non-maleficence, beneficence and justice that result.

The unfair hindrances faced by IMGs are irreconcilable with principles of equity and mateship that are at the core of Australian society. There is still an opportunity for political leaders and medical authorities to rectify these inequities by implementing the recommendations from the parliamentary inquiry and the principles sanctioned in international codes of practice.

Competing interests: No relevant disclosures.

Provenance: Not commissioned; externally peer reviewed.

1 House of Representatives Standing Committee on Health and Ageing Lost in the labyrinth: report on the inquiry into registration processes and support for overseas trained doctors. Canberra: Commonwealth of Australia, 2012. http://www.aph.gov.au/Parliamentary_Business/ Committees/House_of_Representatives_Committees?url=haa/ overseasdoctors/report.htm (accessed Jul 2014).

2 Douglas S. The registration and accreditation of international medical graduates in Australia: a broken system or a work in progress? People Place 2008; 16: 28-40. http://arrow.monash.edu.au/vital/access/services/ Download/monash:64145/DOC (accessed Jul 2014).

3 Zubaran C. Balancing the act: the international migration of medical graduates. Monash Bioeth Rev 2011; 29: 1-12.

4 Robinson M, Slaney GM. Choice or chance! The influence of decentralised training on GP retention in the Bogong region of Victoria and New South Wales. Rural Remote Health 2013; 13: 2231.

5 Grant HM. From the Transvaal to the prairies: the migration of South African physicians to Canada. J Ethn Migr Stud 2006; 32: 681-695. doi: 10.1080/13691830600610098.

6 Cowling K. IMG's $\$ 1000$ bill for treating own child. 6minutes $2013 ; 12$ Jun.

7 Department of Immigration and Citizenship. Visa Subclass 457 Integrity Review. Final report. 2008. https://www.immi.gov.au/skilled/skilledworkers/_pdf/457-integrity-review.pdf (accessed Jul 2014).

8 Commonwealth code of practice for the international recruitment of health workers. Adopted at the Pre-World Health Assembly Meeting of the Commonwealth Health Ministers 2003. Geneva: 18 May, 2003. http://www. plexusrecruitment.com.au/public/editor_images/Commonwealth_Code_ of_Practice.pdf (accessed Sep 2014).

9 World Health Organization. WHO global code of practice on the international recruitment of health personnel. Geneva: WHO, 2010. http:// www.who.int/hrh/migration/code/full_text/en (accessed Jul 2014).

10 Nair BK, Searles AM, Ling RI, et al. Workplace-based assessment for international medical graduates: at what cost? Med J Aust 2014; 200: 41-44. 